\title{
Role of the North Pacific sea surface temperature in the East Asian winter monsoon decadal variability
}

\author{
Jianqi Sun ${ }^{1,2} \cdot$ Sha $\mathrm{Wu}^{1,2} \cdot$ Juan Ao ${ }^{1,2}$
}

Received: 28 January 2015 / Accepted: 14 August 2015 / Published online: 26 August 2015

(C) The Author(s) 2015. This article is published with open access at Springerlink.com

\begin{abstract}
In this study, a possible mechanism for the decadal variability in the East Asian winter monsoon (EAWM) is proposed. Specifically, the North Pacific sea surface temperature (SST) may play an important role. An analysis of the observations shows that the North Pacific SST has a remarkable decadal pattern whose phase shifted around the mid-1980s. This North Pacific SST decadal pattern can weaken the East Asian trough and enhance the North Pacific Oscillation through changing air-sea interactions over the North Pacific. The weak East Asian trough enhances the zonal circulation and weakens the meridional circulation over East Asia, consequently leading to a weaker southward cold surge and East Asia warming around the mid-1980s. The numerical experiment further confirms the pronounced physical processes. In addition, over the longer period of 1871-2012, the indices of the EAWM and North Pacific SST decadal pattern are also highly consistent on the decadal timescale, which further confirms the impact of the North Pacific SST decadal pattern on the EAWM decadal variability.
\end{abstract}

Keywords East Asian winter monsoon - Sea surface temperature $\cdot$ Decadal variability $\cdot$ Atmospheric circulation $\cdot$ East Asian trough $\cdot$ North Pacific Oscillation

Jianqi Sun

sunjq@mail.iap.ac.cn

1 Nansen-Zhu International Research Center, Institute of Atmospheric Physics, Chinese Academy of Sciences, PO Box 9804, Beijing 100029, China

2 University of Chinese Academy of Sciences, Beijing 100049, China

\section{Introduction}

The East Asian monsoon is one of the most active climate systems in the Northern Hemisphere (e.g., Lau and Li 1984; Tao and Chen 1987; Matsumoto 1992; Ding 1994). The climate anomalies associated with the East Asian monsoon have a strongly variable intensity that can result in extreme events, such as droughts, floods, intense snowfall, and cold surges; these events have a profound impact on people's livelihoods, society, and the natural environment in East Asia. In addition, the East Asian monsoon can drive the atmospheric general circulation and affect the climate variability in distant regions (e.g., Li and Mu 2000; Yang et al. 2002; Lau and Weng 2002; Chang et al. 2005; Zhou et al. 2007). Therefore, the variability in the East Asian monsoon and its causes have been greatly emphasised in the literature.

Observational analysis shows that the East Asian summer monsoon (EASM) significantly weakened around the late 1970s (e.g., Wang 2001; Wu and Wang 2002; Gong and Ho 2002; Hu et al. 2003; Han and Wang 2007; Ding et al. 2008). Studies on the EASM-related mechanisms indicated that this EASM decadal weakening is largely attributable to the variations in the sea surface temperature (SST). For example, the tropical Pacific and Indian Ocean SST decadal variability may play an important role (Chang et al. 2000; Gong and Ho 2002; Hu et al. 2003; Yang and Lau 2004; Li et al. 2008, 2010 Zhou et al. 2009). The extratropical SST interdecadal modes, i.e., the Pacific Decadal Oscillation (PDO) and Atlantic Multi-decadal Oscillation (AMO), are also contributors (Yang et al. 2005; Ma and Shao 2006; Lu et al. 2006; Wang et al. 2009a; Zhu et al. 2011). Recently, Wang et al. (2013) indicated that human activities were a prime driver of the shift in the EASM in 
the late 1970s, while the SST variability is still an important method of transferring the impact of human activities to the EASM.

In contrast to the EASM, which experienced a decadal shift around the late 1970s, the East Asian winter monsoon (EAWM) showed decadal weakening around the mid-1980s (e.g., Shi 1996; Xu et al. 1999; Jhun and Lee 2004; Wang et al. 2009b; Wang and He 2012; He and Wang 2012; Sun and Ao 2013; Ding et al. 2014). This decadal weakening of the EAWM resulted in an increase in the winter surface air temperature, a decrease in the frequency of cold waves, and abundant and extreme precipitation over East Asia in the last three decades.

Most studies have focused on the interannual time scale of the EAWM variability. It has been found that the EAWM interannual variability is closely related to the Siberian High (Ding and Krishnamurti 1987; Gong et al. 2001), the Aleutian Low (Overland et al. 1999), the East Asian trough (Sun and Li 1997; Wang et al. 2009b), the North Atlantic Oscillation (NAO)/Arctic Oscillation (AO) (Wu and Huang 1999; Gong et al. 2001), El Niño-Southern Oscillation (ENSO) (Li 1990; Zhang et al. 1996; Wang and He 2012), the East Asian jet stream (Yang et al. 2002), the stationary planetary wave activity (Chen et al. 2005), and the snow cover over Eurasia (Watanabe and Nitta 1999). Recent studies also showed that the EAWM is closely related to Arctic sea ice content (Liu et al. 2012; Li et al. 2014). Among these factors, some have an unstable impact on the EAWM. For example, Wang and He (2012) found that the connection between the EAWM and ENSO was significantly weaker after the late 1970s; thus, predicting the interannual variability in the EAWM became difficult.

Compared with the interannual variability, studies on the decadal variability in the EAWM are rare, and the cause of the decadal shift in the EAWM around the mid1980s remains unclear. After diagnosing the atmospheric circulation associated with the decadal EAWM variability, Jhun and Lee (2004) deduced that the AO may contribute to the decadal variability in the EAWM. Under global warming, models have shown a weakening EAWM; thus, global warming is also considered a factor that impacts the EAWM's decadal shift (Hori and Ueda 2006).

In climate systems, the decadal SST mode is generally considered a major source of the climate decadal shift. For example, the most common SST decadal modes (e.g., the PDO, AMO, tropical Atlantic decadal warming mode, etc.) greatly contributed to the climate shift around the late 1970s (e.g., Trenberth and Hurrell 1994; Zhang et al. 1997a; Kerr 2000; Delworth and Mann 2000; Dong et al. 2006; Sun et al. 2009). Some studies also indicated that the PDO may contribute to the EAWM decadal variability. However, the PDO phase shift over past half century occurred around the late 1970s, leading the decadal shift in the EAWM by approximately 10 years. Because the atmosphere quickly responds to external forcing, the PDO variability with a lead time of approximately 10 years may not easily explain the EAWM weakening around the mid-1980s. Therefore, a natural question arises: is there any other decadal SST mode that contributed to the decadal shift in the EAWM around the mid-1980s? This study attempts to answer this question.

The remainder of the paper is organised as follows. The datasets and methods used in the present study are described in Sect. 2. Section 3 introduces the observed EAWM-related atmospheric and SST patterns. The possible link between the North Pacific SST decadal pattern and the EAWM according to a numerical simulation is presented in Sect. 4. Section 5 provides a discussion and conclusions.

\section{Datasets and methods}

The atmospheric circulation dataset used in this study is the monthly mean reanalysis from the National Centers for Environmental Prediction-National Center for Atmospheric Research (Kalnay et al. 1996). The NCEP-NCAR reanalysis data are available after 1948 and are gridded at $2.5^{\circ} \times 2.5^{\circ}$ resolution. Because the quality of the NCEPNCAR reanalysis data on a decadal time scale is debatable, the reanalysis dataset (ERA-40) produced by the European Centre for Medium-Range Weather Forecasts (Uppala et al. 2005) is used to confirm the robustness of the results identified with the NCEP-NCAR reanalysis. The ERA-40 data are gridded at a $2.5^{\circ} \times 2.5^{\circ}$ resolution over 1957-2002.

To obtain the long-term EAWM decadal variability, the Twentieth Century Reanalysis version 2 (20CR V2) over 1871-2012 (Compo et al. 2011) is used. In addition, the AO index data obtained at http://www.esrl.noaa.gov/psd/ data/20thC_Rean/timeseries/monthly/AO/ (1871-2012) are employed to investigate the relationship between the $\mathrm{AO}$ and EAWM on a decadal time scale. To discuss the connection between global warming and EAWM decadal variability, the Northern Hemisphere warming index at http://www. cru.uea.ac.uk/cru/data/temperature/ (1871-2012) is used.

The SST data gridded at a $2^{\circ} \times 2^{\circ}$ resolution are the Extended Reconstructed Sea Surface Temperature version 3b (ERSST V3b), which are from the National Oceanic and Atmospheric Administration (NOAA), Earth System Research Laboratory (ESRL) (Smith and Reynolds 2003). The SST dataset is available after 1854 .

The EAWM index (EAWMI) is defined as the negative mean geopotential height at $500 \mathrm{hPa}$ within $25^{\circ}-45^{\circ} \mathrm{N}$ and $110^{\circ}-145^{\circ} \mathrm{E}$, where the East Asian trough is located; this area reflects the variations in the EAWM-related circulation (Sun and Li 1997; Wang et al. 2009b; Wang and He 2012). In this paper, the December-January-February mean 
represents the boreal winter. For example, the winter of 1949 refers to the average of December 1948, January 1949 and February 1949.

\section{Observed EAWM-related atmospheric and SST patterns}

Figure 1a shows the EAWM index from the NCEP-NCAR data over the period of 1949-2014. Similar to previous studies (e.g., Shi 1996; Xu et al. 1999; Jhun and Lee 2004; Wang et al. 2009b; Wang and He 2012; He and Wang 2012; Sun and Ao 2013; Ding et al. 2014), the EAWM index shows a strong interannual variability and a decadal shift around the mid-1980s. A $t$ test analysis indicates that the decadal change in the EAWM around the mid-1980s is significant. After the mid-1980s, the EAWM significantly weakened, and its variability decreased. The EAWM index from ERA-40 exhibits highly consistent results (Fig. 1b). The correlation coefficients between the two indices over 1958-2002 is 0.98 , and the two indices have a consistent decadal shift around the mid-1980s. Based on these two EAWM indices, the entire analysis period is divided into two 20-year (1966-1985 and 1988-2007 for NCEP-NCAR) and 15-year (1971-1985 and 1988-2002 for ERA-40) sub-periods to investigate the possible cause of the decadal change in the EAWM around the mid-1980s.

Figure 2a shows the decadal differences in the geopotential height at $500 \mathrm{hPa}$ from the NCEP-NCAR data. Along with the weakening EAWM, the changes in the geopotential height show a meridional dipole pattern from East Asia to North America, with negative anomalies over high latitudes and positive anomalies over middle to low latitudes. The meridional dipole pattern over the North Pacific is referred to as the NPO (Walker and Bliss 1932). Figure 2a indicates the phase shift in the NPO around the mid1980s, which is consistent with a recent study (Pak et al. 2014). Pak et al. (2014) further showed that the connection between the EAWM and NPO was essentially broken after mid-1980s.

It is well known that the East Asian trough is a dominant system over East Asia; the trough can steer cold air southeastward from the high latitudes to East Asia (Zhang et al. 1997b). Figure 2a shows significantly positive geopotential heights over East Asia; thus, the East Asian trough weakened around the mid-1980s. A weaker East Asian trough will lead to a more zonal circulation in the mid-to-high latitudes, which weakens the southward invasion of the cold air from the high latitudes.

In addition to the East Asian trough, Jhun and Lee (2004) indicated that the changes in the East Asian
Fig. 1 Normalised EAWM index: year-to-year variability (bar), nine-year running means (solid line), and two sub-periods' means (dash line) calculated from a NCEP-NCAR and b ERA-40 (a)

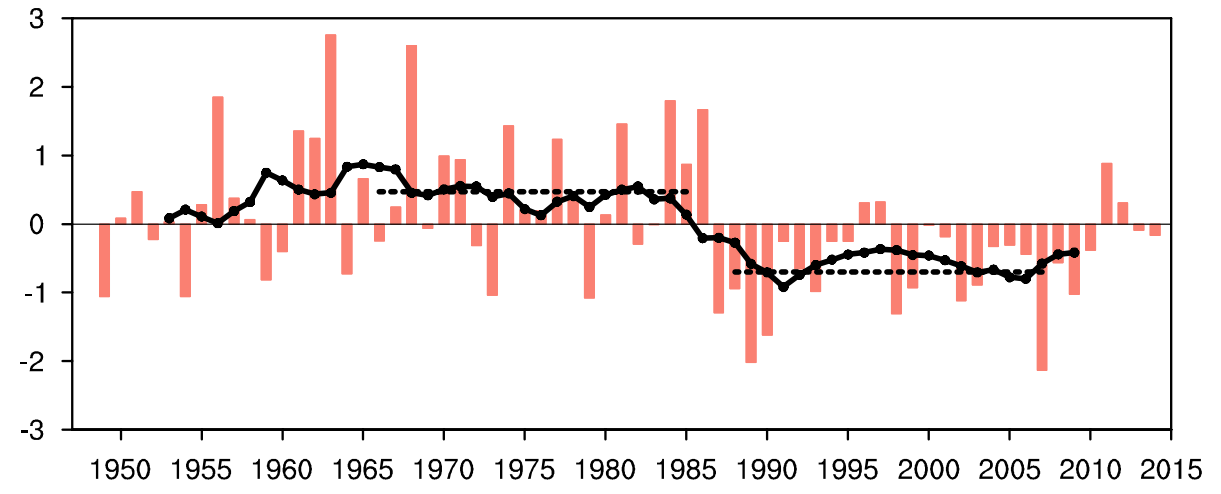

(b)

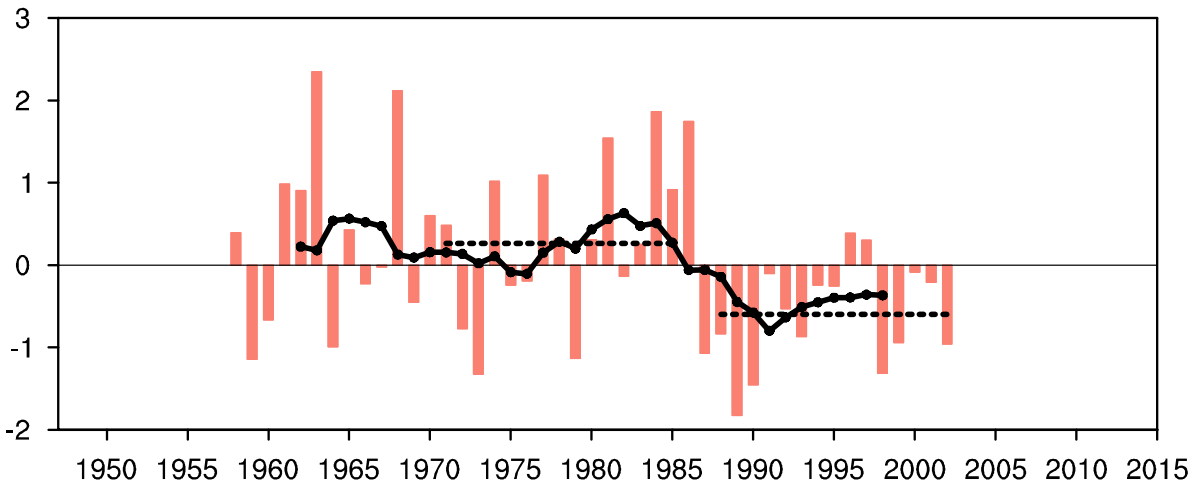


Fig. 2 Decadal differences in a $500 \mathrm{hPa}$ geopotential heights, b $300 \mathrm{hPa}$ zonal winds, and c $850 \mathrm{hPa}$ horizontal winds from NCEP-NCAR between 1988-2007 and 1966-1985. The light (dark) shading indicates the areas significant at the $90 \%$ (95\%) confidence level. The rectangle in (a) is the area used to compute the EAWM index

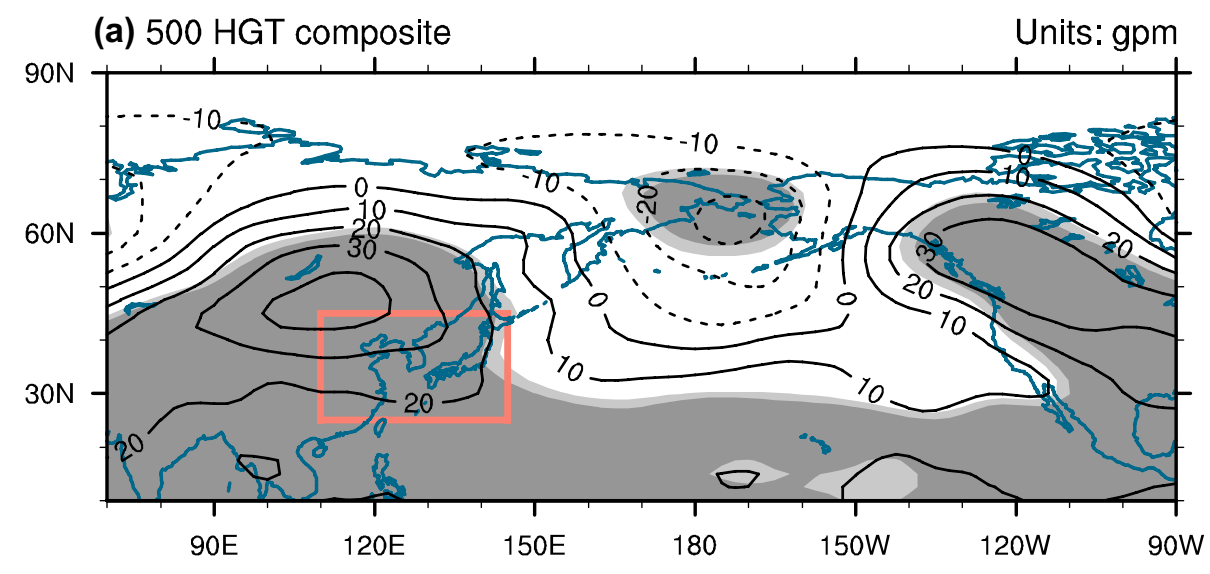

(b) $300 \mathrm{hPa} U$ composite

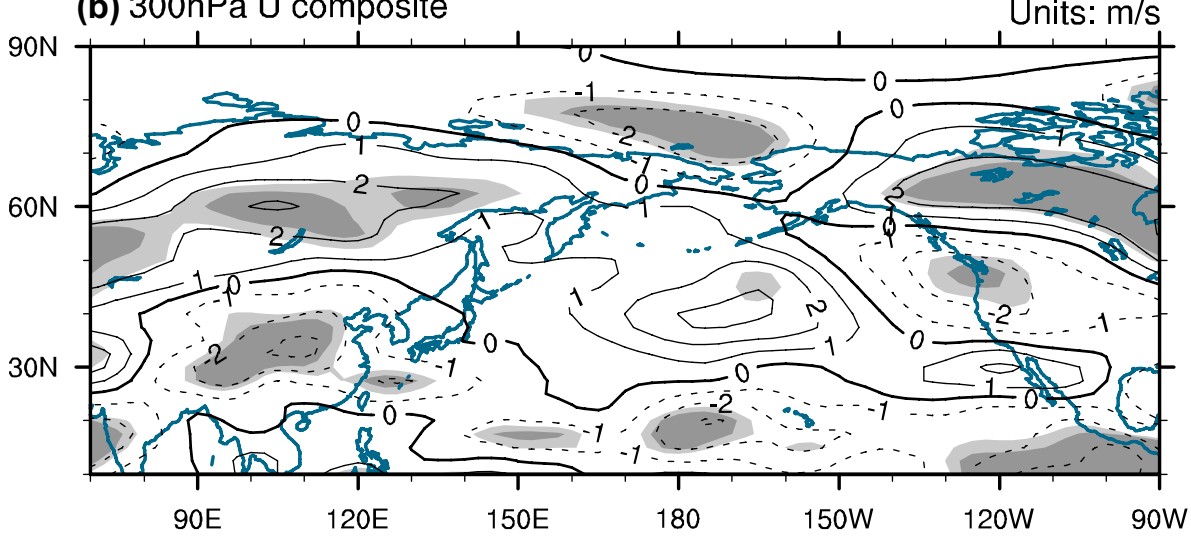

(c) $850 \mathrm{hPa}$ UV composite

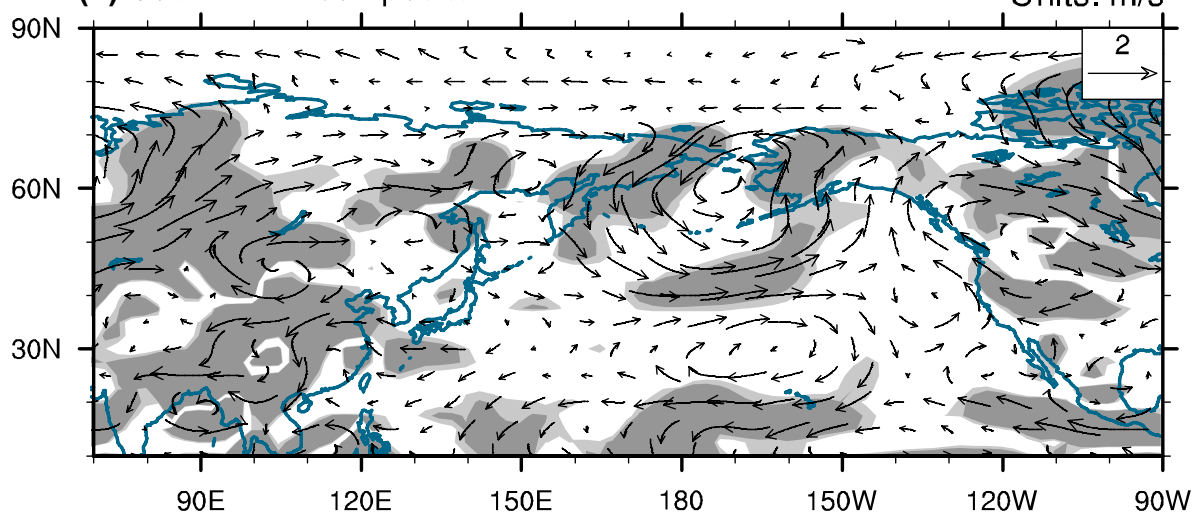

upper level jet stream can also reflect the intensity of the EAWM. The authors further defined an EAWM index using the $300 \mathrm{hPa}$ meridional zonal wind shear. Comparing Fig. $2 b$ in this study and Fig. 2 in their paper, the enhanced zonal wind over the East Asian mid-to-high latitudes and weakened zonal wind over the mid-to-low latitudes in Fig. $2 b$ indicates weakening of the EAWM.

Under such an atmospheric circulation, there are prevailing anomalous south-westerly winds over northern East Asia at the low levels (Fig. 2c). Compared with the climatology, the anomalous south-westerly winds can weaken the dominant north-westerly winds over East Asia and thus prohibit the southward invasion of cold air from the high latitudes to East Asia.

The atmospheric circulations associated with the decadal change in the EAWM in the ERA-40 data are depicted in Fig. 3. Generally, the two datasets exhibit consistent results. Because of the short time period of the ERA-40 data, the analysis sub-period for the ERA-40 data is only 15 years, whereas the NCEP-NCAR data sub-period is 
Fig. 3 Decadal differences in a $500 \mathrm{hPa}$ geopotential heights, b $300 \mathrm{hPa}$ zonal winds, and c $850 \mathrm{hPa}$ horizontal winds from ERA-40 between 1988-2002 and 1971-1985. The light (dark) shading indicates the areas significant at the $90 \%$ (95\%) confidence level

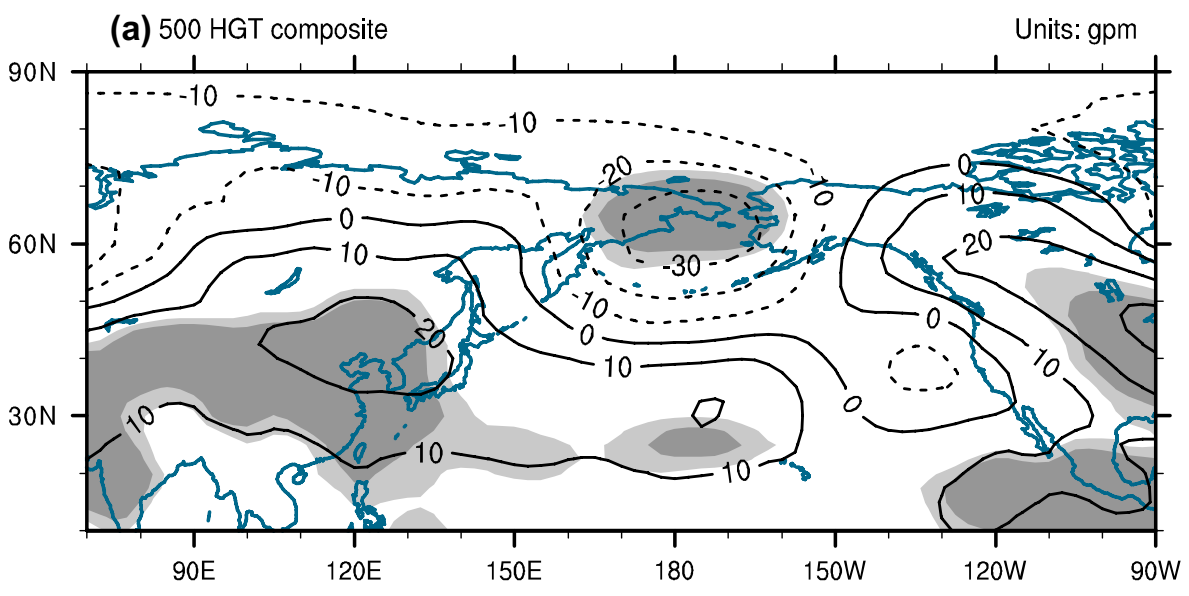

(b) $300 \mathrm{hPa} U$ composite

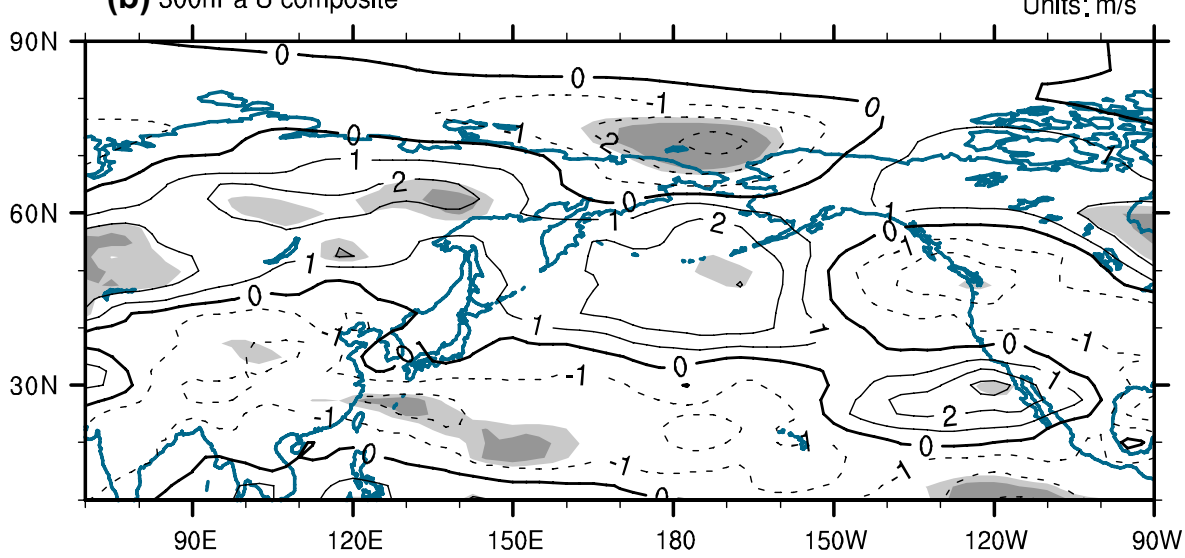

(c) $850 \mathrm{hPa}$ UV composite

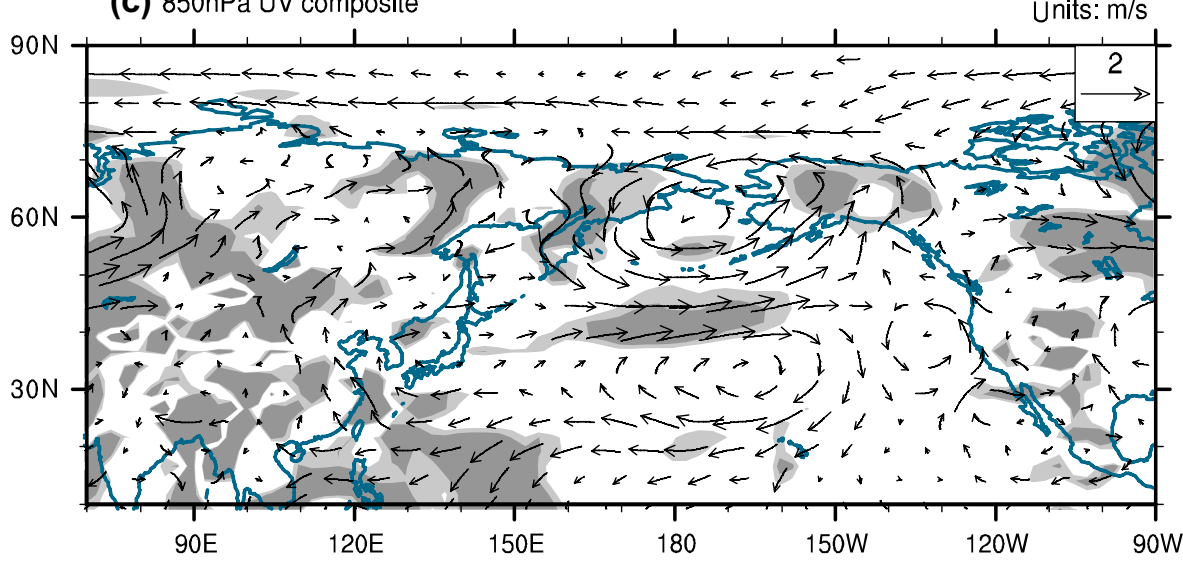

20 years. If the analysis period for the NCEP-NCAR data is also confined to the same 15 -year sub-period as the ERA-40 data, then the distribution, intensity, and significance of the atmospheric circulations in these two data are more similar. A relatively larger difference occurs over the Mongolian region. The atmospheric circulation anomaly in the NCEP-NCAR data is larger than that in the ERA40 data. Such a difference over the region between the two reanalysis datasets should be attributed to the larger bias of the NCEP-NCAR data in the 1960s and 1970s (Yang et al. 2002; Inoue and Matsumoto 2004). Thus, ERA-40 should reflect more reliable variability in the EAWM for specific features.

Consistent with the decadal change in the atmospheric circulation, the North Pacific SST also exhibits a significant decadal change around the mid-1980s. As shown in Fig. 4, strongly positive anomalous SST zones are located over the southwestern North Pacific and high latitudes of the North 
Fig. 4 Decadal differences in the SST between 1988-2007 and 1966-1985. The light (dark) shading indicates the areas significant at the $90 \%$ (95\%) confidence level. The rectangle is the area used to compute the SST index

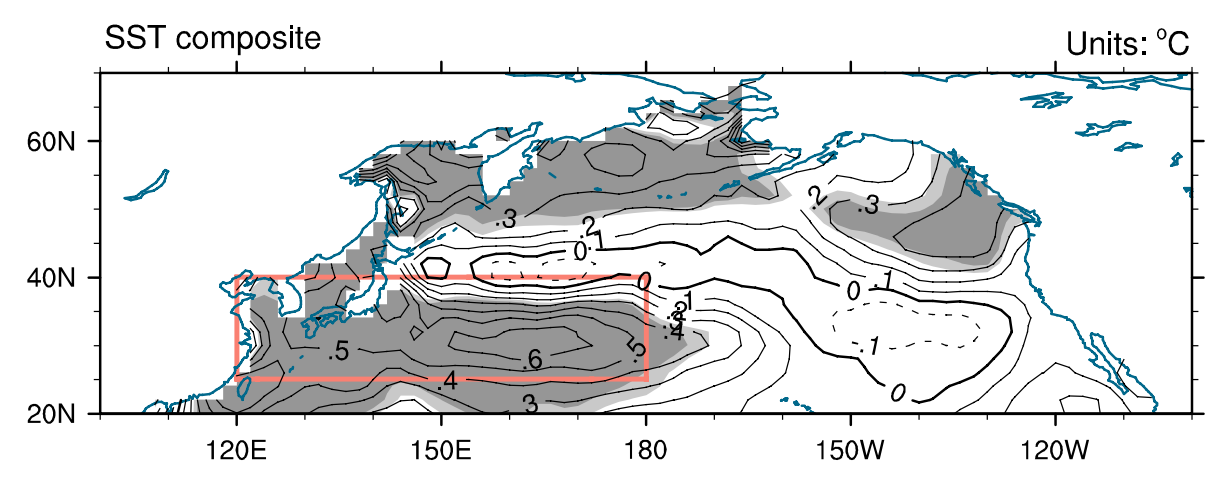

Turbulent Heat Flux composite

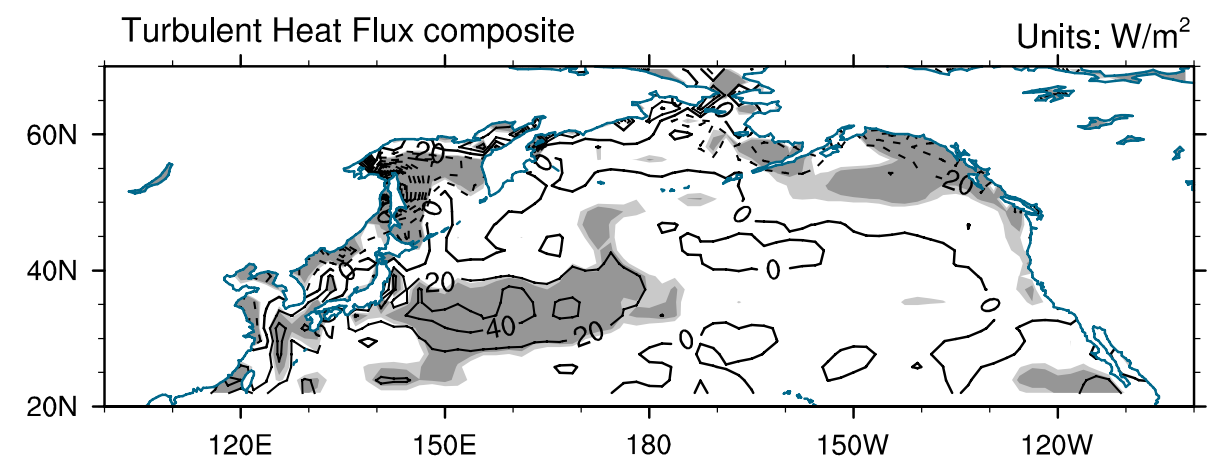

Fig. 5 Decadal differences in the turbulent heat fluxes from NCEP-NCAR between 1988-2007 and 1966-1985. The light (dark) shading indicates the areas significant at the $90 \%$ (95\%) confidence level. The positive value indicates the upward and negative indicates the downward
Pacific; between these areas is a narrow and weak negative SST zone from the western mid-North Pacific to the southeastern North Pacific.

The air-sea interaction over the mid-latitude ocean could differ with timescale. Bjerknes (1964) suggested that the atmosphere was thought to drive directly most the shortterm SST variability and the ocean to contribute significantly to long-term SST and atmosphere variability. Later researches confirm the Bjerknes conjecture. Based on the coupled model simulation, some studies concluded that the decadal climate variability over the North Pacific is an inherently air-sea coupled phenomenon, while the slow dynamical adjustments of the ocean are crucial in setting the decadal SST mode and the atmosphere responds passively and feed back to the SST decadal variability (e.g., Latif and Barnett 1994, 1996; Latif 2006; An 2008). On the observation aspect, Gulev et al. (2013) provided evidence that, on the decadal timescale, the turbulent heat flux is indeed driven by the ocean and may force the atmosphere, and Zhang and Levitus (1997) proposed the subtropical subsurface ocean process may contribute to establishing the decadal SST variability in the mid-latitude North Pacific, which, in turn, influences the atmospheric circulation. In this study, to further investigate the relative role of the atmosphere and ocean in the East Asia-North Pacific climate decadal change around the mid-1980s, the related decadal changes in wind stress and wind stress curl were calculated (figure not shown). It is found that the decadal changes in the atmospheric circulation can generally result in anomalous downwelling Ekman pumping in the southern North Pacific and upwelling Ekman pumping in the northern. However, these Ekman pumping anomalies are weak and do not correspond well to the significant SST warming over the southwestern North Pacific. Thus the decadal SST anomaly over the southwestern North Pacific could not be dominated by the atmosphere change, although the atmosphere has a positive feedback. Besides the wind stress and its related dynamical process, the surface heat flux is also important language of the ocean-atmosphere communication (Gulev et al. 2013). Thus, the turbulent heat flux (sensible plus latent heat fluxes) is further diagnosed. Figure 5 suggests that the large-scale upward directed turbulent heat flux is located over the southwestern North Pacific, corresponding well to the warming SST over the region, indicating that the warming SST over the southwestern North Pacific releases energy and heats the overlying atmosphere. Thus the ocean dynamics could play an important role in the generation of the decadal SST anomaly over the southwestern North Pacific, which further influences its overlying atmosphere variability.

Over the cool SST region, the changes in the turbulent heat flux are not strong. In contrast to the warm SST over the southwestern North Pacific, the significant SST warming over the high latitude North Pacific along the continental margin corresponds to a downward turbulent heat flux, which indicates that the SST warming over the region could result from energy absorption from the overlying atmosphere. Thus, the warm SST over the high latitude 
Fig. 6 Normalised North Pacific SST decadal pattern index: year-to-year variability (bar), nine-year running means (solid line), and two sub-periods' means (dash line)

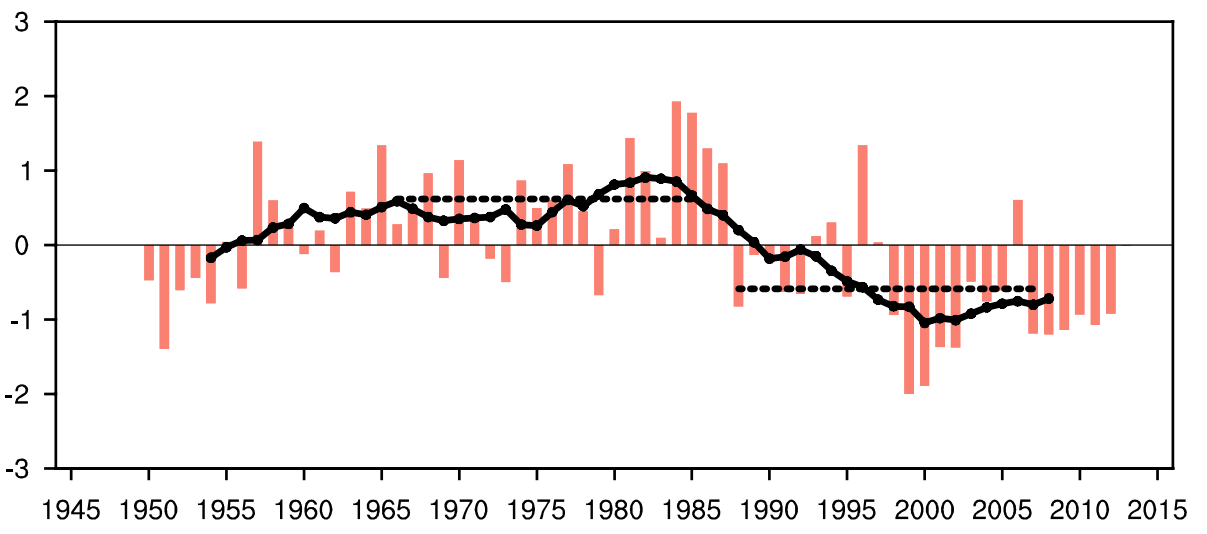

(a) EOF 2

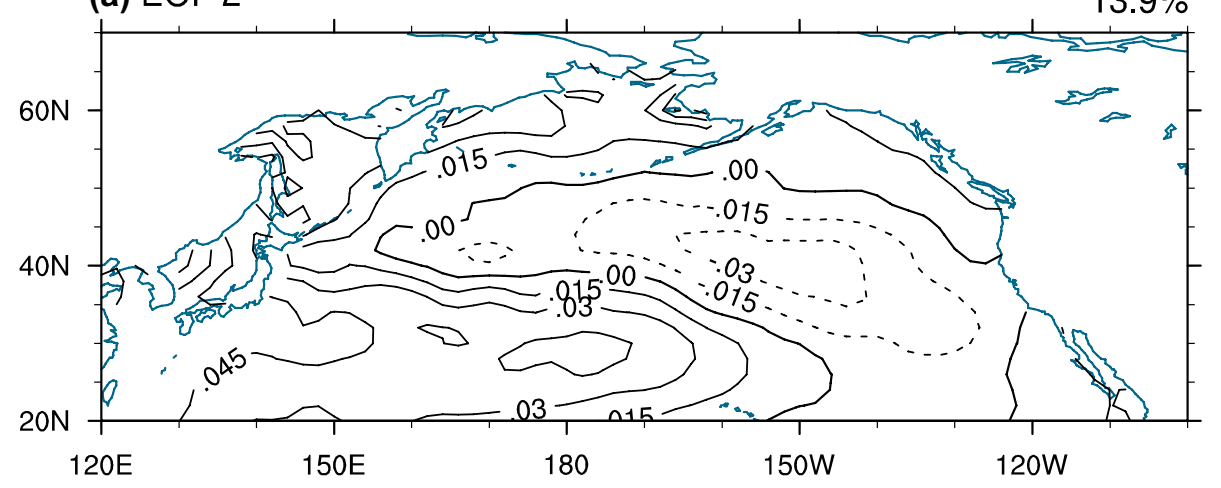

(b) PC of EOF2

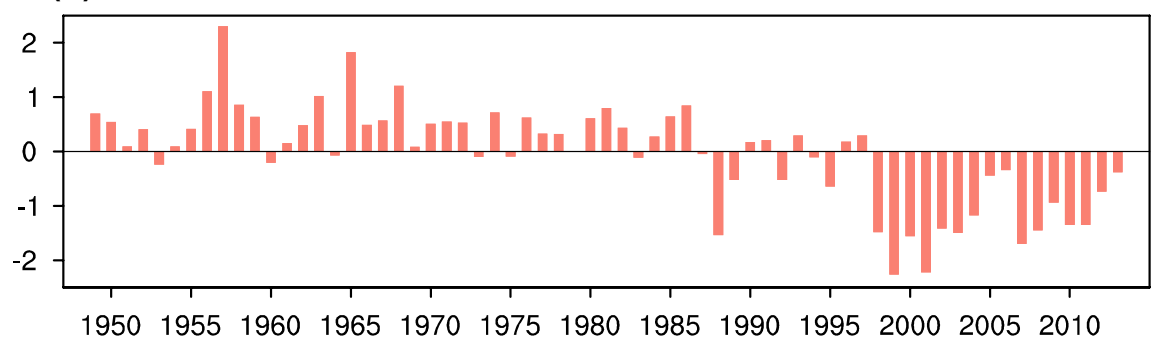

North Pacific could be a response to the atmospheric variability. The distribution of the anomalous turbulent heat flux from NCEP-NCAR in Fig. 5 is further confirmed by the International Comprehensive Ocean-Atmosphere Data Set (figure not shown).

Combining the SST and turbulent heat flux variability, we can deduce that the key oceanic region associated with the decadal change in the atmospheric circulation around the mid-1980s could be the southwestern North Pacific. Then, a North Pacific SST decadal pattern index is defined as the negative averaged SST over the key warming region $\left(120^{\circ}-180^{\circ} \mathrm{E}, 26^{\circ}-40^{\circ} \mathrm{E}\right)$. As shown in Fig. 6, the SST index exhibits a strong decadal variability. Around the mid1980s, the SST index exhibits a consistent decadal shift with the EAWM. A $t$ test analysis indicates that the decadal change in the SST index is significant.
It is well known that the leading empirical orthogonal function (EOF) mode of the SST variability over the North Pacific is the PDO pattern. The second EOF mode of the SST variability over the North Pacific in Fig. 7 shows a highly consistent spatial pattern, with the decadal change pattern of the North Pacific SST occurring around the mid1980s (Fig. 4). The spatial correlation coefficient between the SST patterns in Figs. 4 and 7 is 0.79, and the time series of the second EOF mode co-varies with the variability in the pronounced SST decadal pattern, with a correlation of 0.74 over the period of 1949-2013. Bond et al. (2003) has showed that the EOF2-type SST mode has a contribution to the decadal shift of the North Pacific state in the winter half-year (November to March) around late 1990s. In this study, on one hand the decadal SST pattern around the mid1980s is similar to the EOF2 SST mode; on the other hand 
the decadal SST pattern also exhibits some differences with the EOF2 SST mode. For example, in Fig. 4 the positive signal is strong and the negative signal is weak. In contrast, the positive and negative signals are almost comparable in Fig. 7. In addition, the North Pacific SST decadal pattern can explain about $55 \%$ of the variance of the EOF2 SST mode. Thus the decadal SST pattern revealed in this study not only exhibits some variability of the EOF2 SST mode and also presents its own variability feature; it is an EOF2-like SST decadal pattern, dominating over the North Pacific.

\section{Results of the numerical simulation}

The response of the atmosphere to an extratropical warm SST anomaly is complicated. Whether a ridge or trough responds to warm SSTs is debatable (e.g., Palmer and Sun 1985; Ting 1991; Kushnir and Lau 1992; Lau and Nath 1994; Ferranti et al. 1994; Latif and Barnett 1994; Peng et al. 1995, 1997; Sutton and Hodson 2005; Zhao et al. 2012; Sun 2014). In this study, along with the decadal SST warming over the southwestern North Pacific, the overlying atmosphere shows barotropic positive anomalies (Fig. 8). The indubitable cause-effect relationship between the warm SST and the barotropic ridge response needs to be confirmed by numerical simulations.

Here, the sensitivity experiments were performed with the global Community Atmosphere Model (CAM5), which

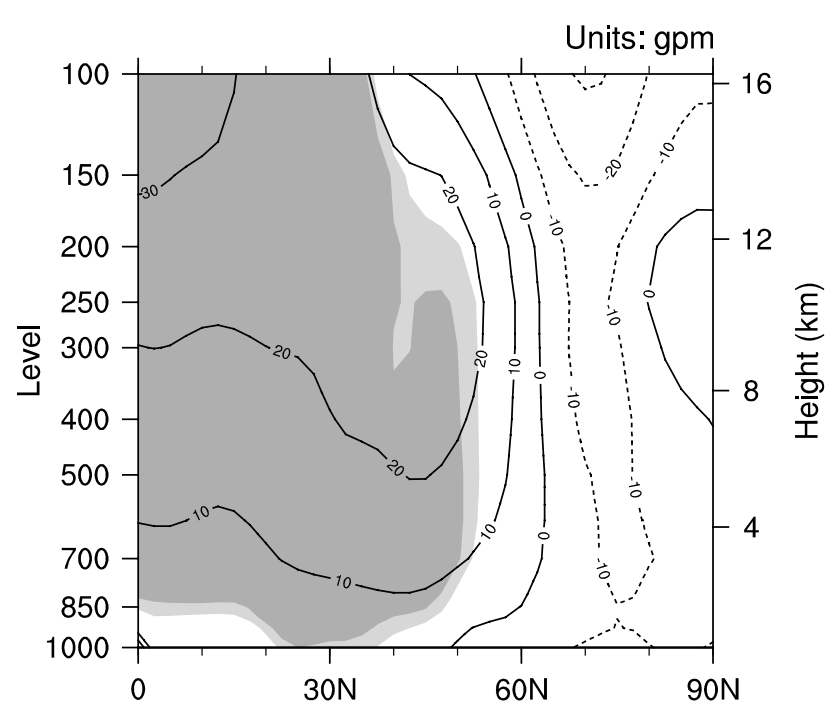

Fig. 8 Decadal differences in the latitude-pressure cross-section of the geopotential heights averaged along $100^{\circ} \mathrm{E}-180^{\circ} \mathrm{E}$ between $1988-$ 2007 and 1966-1985. The light (dark) shading indicates the areas significant at the $90 \%(95 \%)$ confidence level

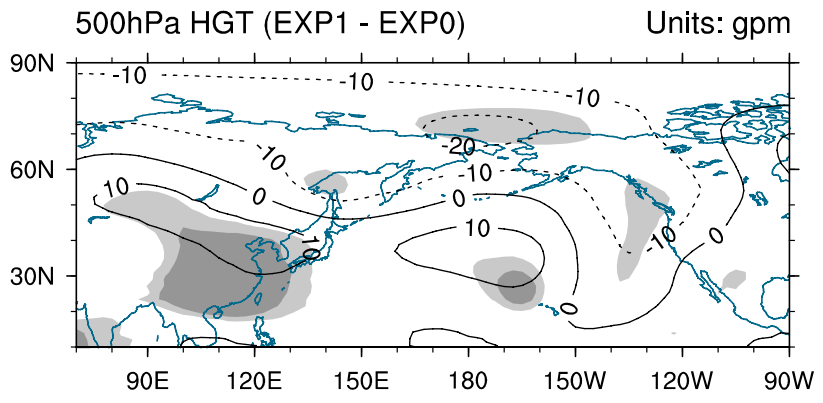

Fig. 9 Differences in the $500 \mathrm{hPa}$ geopotential heights between the sensitivity experiment (EXP1) and control run (EXP0). The light (dark) shading indicates the areas significant at the $90 \%$ (95\%) confidence level

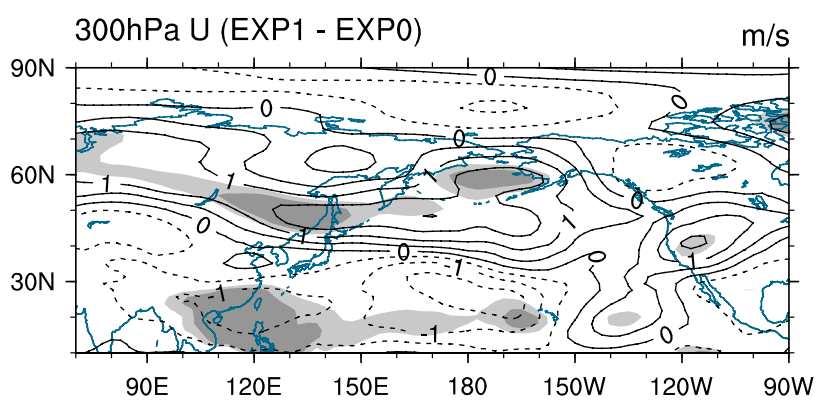

Fig. 10 Differences in $300 \mathrm{hPa}$ zonal wind between the sensitivity experiment (EXP1) and the control run (EXP0). The light (dark) shading indicates the areas significant at the $90 \%$ (95\%) confidence level

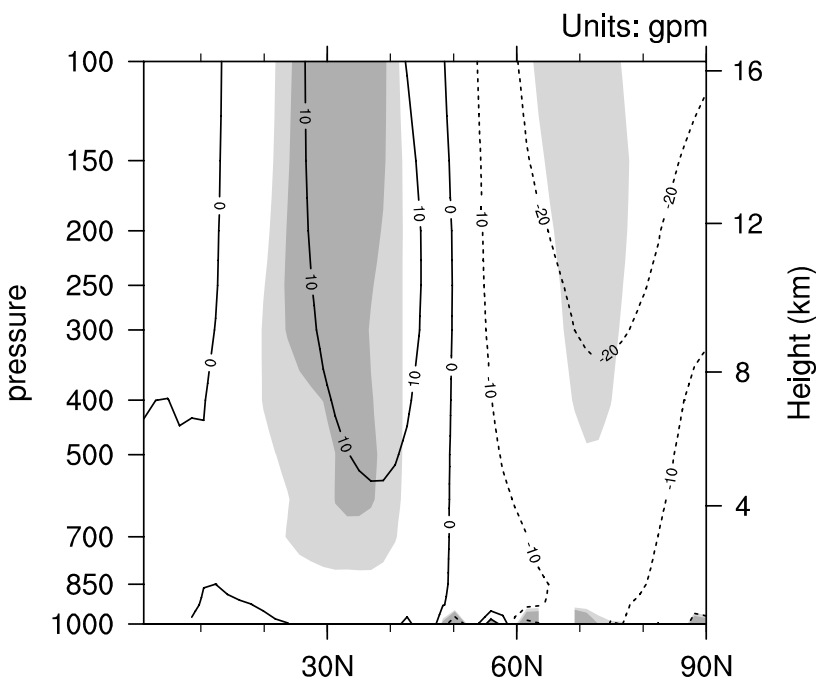

Fig. 11 Differences in the latitude-pressure cross-section of the geopotential heights averaged along $100^{\circ} \mathrm{E}-180^{\circ} \mathrm{E}$ between the sensitivity experiment (EXP1) and the control run (EXP0). The light (dark) shading indicates the areas significant at the $90 \%$ (95\%) confidence level 


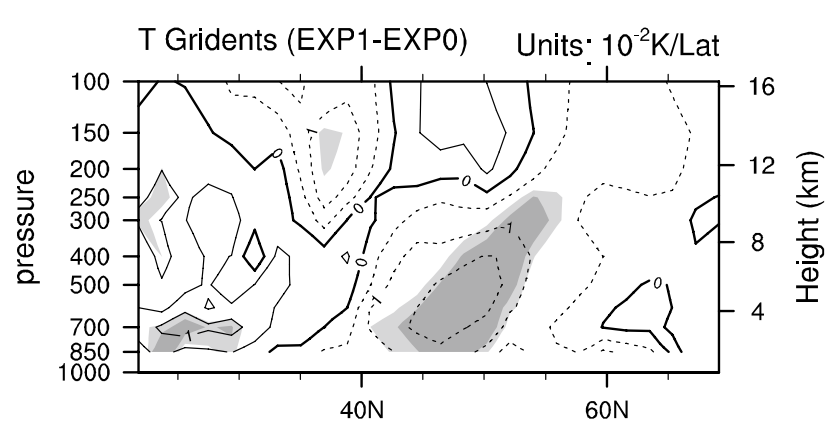

Fig. 12 Differences in the latitude-pressure cross-section of the meridional temperature gradient averaged along $120^{\circ} \mathrm{E}-180^{\circ} \mathrm{E}$ between the sensitivity experiment (EXP1) and the control run (EXP0). The light (dark) shading indicates the areas significant at the $90 \%(95 \%)$ confidence level. And the negative value indicates the meridional temperature gradient is enhanced

is the atmospheric component of the Community Earth System Model (CESM1_0_5). The "F_2000" component set was selected for CESM1_0_5, which used a prescribed climatology for SST and sea ice and an active land model (Community Land Model; CLM) coupled to CAM5. The atmospheric composition was constant in the year 2000, with a $\mathrm{CO}_{2}$ concentration of $367.0 \mathrm{ppm}$ during the simulations. The simulations used a $1.9^{\circ} \times 2.5^{\circ}$ finite volume grid, with 26 hybrid sigma pressure levels and a 30-min integration time step. Detailed information on the model can be found in Gent et al. (2011).

We performed two sets of model simulations. First, a 55-year run with the model's climatological SST and sea ice boundary conditions was performed, and the average for the last 40 years was defined as the control run (EXP0). In the sensitivity experiment, an idealised SST is constructed by imposing the North Pacific SST decadal pattern in Fig. 4 on the monthly climatological SSTs; then, a 55-year run was performed with the idealised SST and sea ice boundary conditions. The average over the last 40 years was defined as the sensitivity experiment run (EXP1). The difference between EXP1 and EXP0 reflects the impact of the North Pacific SST decadal pattern on the change in the atmospheric circulation. The 40-year mean values were equivalent to the values from an ensemble of 40 sensitivity experiments with SST changes over the North Pacific by means of different initial atmospheric and land surface conditions, similar to previous studies (e.g., Zhao et al. 2012).

Figure 9 suggests that the North Pacific SST decadal pattern can stimulate a meridional dipole circulation from East Asia to the North Pacific. Significantly positive geopotential heights can be found over the mid-latitudes and negative heights are found over high latitudes. In particular, there is an anomalously positive geopotential height centre over East Asia, spanning East China, Korea, and Japan; therefore, the East Asian trough weakened. In addition, the zonal wind shows a meridional dipole pattern over East Asia, with positive values over the mid-tohigh latitudes and negative values over the mid-to-low latitudes (Fig. 10). These changes in the atmospheric circulation indicate a weakened EAWM. The vertical structure indicates that the atmosphere has a barotropic and positive geopotential height response to the SST warming over the southwestern North Pacific (Fig. 11). One possible physical mechanism for the impact of the southwestern North Pacific warming SST on the East Asian trough and jet stream could be attributed to the thermal wind theory. In this study, the strong SST warming is located over the southwestern North Pacific. The warming SST releases energy and heats the overlying atmosphere over the North Pacific portion south of $40^{\circ} \mathrm{N}$, which will increase the meridional temperature gradient north of $40^{\circ} \mathrm{N}$ and reduce the meridional temperature gradient south of $40^{\circ} \mathrm{N}$ (Fig. 12). Based on the thermal wind
Fig. 13 Differences in the surface air temperature between the sensitivity experiment (EXP1) and the control run (EXP0). The light (dark) shading indicates the areas significant at the $90 \%$ (95\%) confidence level
SAT (EXP1 - EXP0)

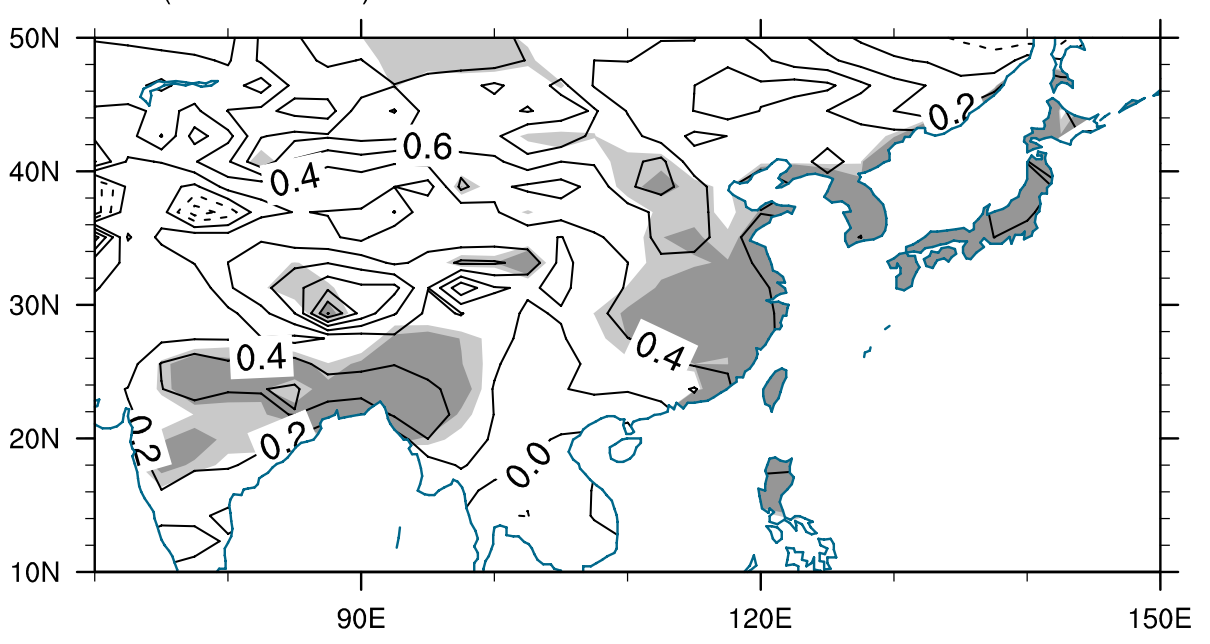




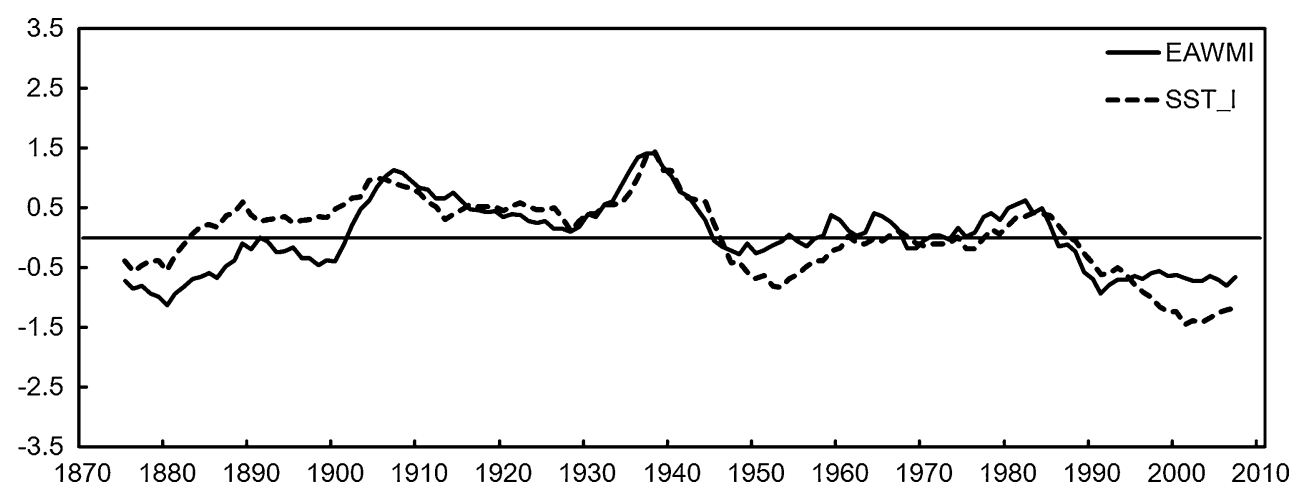

Fig. 14 Nine-year running means of the normalised North Pacific SST decadal pattern and EAWM indices

Fig. 15 Nine-year running means of the normalised $\mathrm{AO}$ and EAWM indices
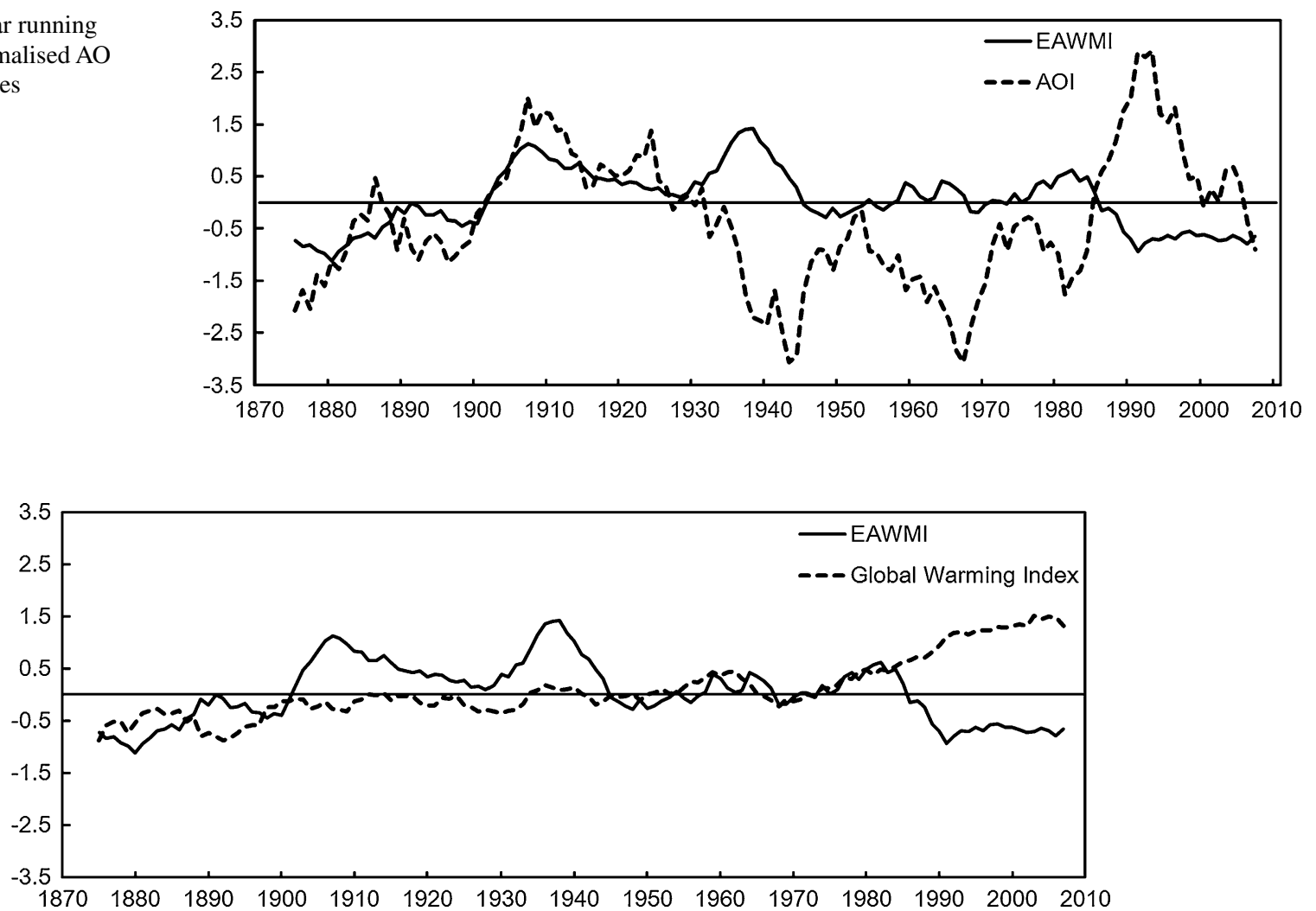

Fig. 16 Nine-year running means of the normalised Northern Hemisphere warming and EAWM indices

theory, the westerly wind over the region north (south) of $40^{\circ} \mathrm{N}$ will be enhanced (weakened). Consequently, a significant anomalous anticyclone (cyclone) occurs over the mid-latitude (high latitude) region from East Asia to the North Pacific, resulting a weakened East Asian trough and EAWM. These responses of the atmospheric circulation to the North Pacific SST decadal pattern in the numerical simulation are quite similar to the observed decadal change in the atmospheric circulation around the mid1980s. These results indicate that the North Pacific SST decadal pattern can weaken the East Asian trough and result in a weakened EAWM, leading to a warmer winter in East Asia (Fig. 13).

Compared with the observations in the last section, the North Pacific SST decadal pattern can reproduce the observed decadal feature of the atmospheric circulation over the North Pacific and East Asia. Nevertheless, the uncertainty in the sensitivity experiment should not be ignored. There are still visible differences in the intensity and position of the atmospheric circulation patterns 
between the simulations and observations, which could be attributed to the climate model's uncertainty in the extratropical climate simulation. Additionally, the observed feature is the result of the air-sea interactions, although the SST could play a more active role. The experiment only allows for one-way interactions; thus, the feedback of the atmospheric to the SST is not considered here. Such shortages could result in biases in the atmospheric simulation as compared with the observations. However, the observed atmospheric features are generally reproduced by the numerical experiment, which confirms the contribution of the North Pacific SST decadal pattern to the EAWM decadal variability.

\section{Conclusion and discussion}

Compared with the interannual variability, the possible cause of the decadal variability in the EAWM is still unclear. In this study, we proposed a factor that could be responsible for the EAWM decadal changes. Along with the decadal change in the EAWM, a dominant SST pattern over the North Pacific exhibits consistent decadal variability. The observations and numerical simulations show that this North Pacific SST decadal pattern can impact the East Asian trough and NPO pattern via changing the air-sea interactions; as a result, the East Asian trough weakens, and a positive NPO pattern occurs. The weakened East Asian trough can lead to a more zonal atmospheric circulation, which can weaken the meridional circulation over East Asia and prohibit the southward invasion of cold air.

Over the past century, the EAWM has exhibited several decadal changes. Does the North Pacific SST decadal pattern contribute to these decadal changes or is it only important to the decadal change around the mid-1980s? To answer this question, the relationship between the EAWM and North Pacific SST decadal pattern was investigated over a long period. Because of the short period of the NCEP-NCAR data, the EAWM was calculated using the 20CR V2 reanalysis based on the same definition as presented in Sect. 2. As shown Fig. 14, over the past 130 years, the two indices reasonably co-varied. In addition to the decadal change around the mid-1980s, these two indices show a consistent decadal change over other periods. If the century-scale variation is removed using the linear detrending method, then the variation in the two indices is more consistent: the correlation coefficient increased from 0.77 pre-detrending to 0.85 post-detrending.

As discussed in the Introduction, previous studies suggested that the $\mathrm{AO}$ and global warming also contribute to the decadal change in the EAWM (Jhun and Lee 2004; Hori and Ueda 2006). However, these factors would only be important to the last decadal change in the EAWM around the mid-1980s. As shown in Figs. 15 and 16, the AO and Northern Hemisphere warming indices only show a decadal variability that is consistent with the EAWM around the mid1980s. Over other periods, the relationship of the AO and global warming with the EAWM is weak. The correlation coefficients with the EAWM index are only 0.09 and 0.23 for the AO and global warming indices, respectively. Thus, the North Pacific SST decadal pattern could be a major factor influencing the EAWM decadal variability. What is more, the EAWM decadal variability is very complicated. Some other boundary forcings (e.g., sea ice) might play a role in the EAWM decadal variability as well, which should be investigated in the future.

Acknowledgments Support for the Twentieth Century Reanalysis Project data set is provided by the US Department of Energy, Office of Science Innovative and Novel Computational Impact on Theory and Experiment (DOE INCITE) program and Office of Biological and Environmental Research (BER), and by the National Oceanic and Atmospheric Administration Climate Program Office. We also thank the British Atmospheric Data Centre for providing ECMWF reanalysis data. This work was jointly supported by the Special Fund for Public Welfare Industry (meteorology) (GYHY201306026) and the National Natural Science Foundation of China (41522503 and 41421004).

Open Access This article is distributed under the terms of the Creative Commons Attribution 4.0 International License (http://creativecommons.org/licenses/by/4.0/), which permits unrestricted use, distribution, and reproduction in any medium, provided you give appropriate credit to the original author(s) and the source, provide a link to the Creative Commons license, and indicate if changes were made.

\section{References}

An S (2008) A mechanism for the multi-decadal climate oscillation in the North Pacific. Theoret Appl Climatol 91:77-84

Bjerknes J (1964) Atlantic air-sea interaction. Adv Geophys 10:1-82

Bond NA, Overland JE, Spillane M, Stabeno P (2003) Recent shifts in the state of the North Pacific. Geophys Res Lett 30:2183. doi:10. 1029/2003GL018597

Chang CP, Zhang YS, Li T (2000) Interannual and interdecadal variations of the East Asian summer monsoon and tropical Pacific SSTs. Part I: roles of the subtropical ridge. J Clim 13:4326-4340

Chang CP, Harr PA, Chen HJ (2005) Synoptic disturbances over the equatorial South China Sea and western Maritime continent during boreal winter. Mon Wea Rev 133:489-503

Chen W, Yang S, Huang RH (2005) Relationship between stationary planetary wave activity and the East Asian winter monsoon. J Geophys Res 110:D14110. doi:10.1029/2004JD005669

Compo GP, Whitaker JS, Sardeshmukh PD et al (2011) The twentieth century reanalysis project. Q J R Meteorol Soc 137:1-28

Delworth TL, Mann ME (2000) Observed and simulated multidecadal variability in the Northern Hemisphere. Clim Dyn 16:661-676

Ding YH (1994) Monsoons over China. Kluwer, Norwell, p 420

Ding YH, Krishnamurti TN (1987) Heat budget of the Siberian high and the winter monsoon. Mon Wea Rev 115:2428-2449

Ding YH, Wang ZY, Sun Y (2008) Inter-decadal variation of the summer precipitation in East China and its association with 
decreasing Asian summer monsoon. Part I: observed evidences. Int J Climatol 28:1139-1161. doi:10.1002/joc.1615

Ding YH, Liu YJ, Liang SJ et al (2014) Interdecadal variability of the East Asian winter monsoon and its possible links to global climate change. Acta Meteorol Sin 72(5):835-852. doi:10.11676/ qxxb2014.079

Dong B, Sutton RT, Scaife AA (2006) Multidecadal modulation of El Niño-Southern Oscillation (ENSO) variance by Atlantic Ocean sea surface temperatures. Geophys Res Lett 33:L08705. doi:10. 1029/2006GL025766

Ferranti L, Molteni F, Palmer TN (1994) Impact of localized tropical and extratropical SST anomalies in ensembles of seasonal GCM integrations. Q J R Meteorol Soc 120:1613-1645

Gent PR, Danabasoglu G, Donner LE et al (2011) The community climate system model version 4. J Clim 24:4973-4991. doi:10.1 175/2011JCLI4083.1

Gong DY, Ho CH (2002) Shift in the summer rainfall over the Yangtze River valley in the late 1970s. Geophys Res Lett 29:10. doi:1 $0.1029 / 2001$ GL014523

Gong DY, Wang SW, Zhu JH (2001) East Asian winter monsoon and Arctic oscillation. Geophys Res Lett 28(10):2073-2076

Gulev SK, Latif M, Keenlyside N et al (2013) North Atlantic Ocean control on surface heat flux on multidecadal timescales. Nature 499:464-468

Han JP, Wang HJ (2007) Features of interdecadal changes of the East Asian summer monsoon and similarity and discrepancy in ERA40 and NCEP/NCAR reanalysis. Chin J Geophys 56:1666-1676 (in Chinese)

He SP, Wang HJ (2012) An integrated East Asian winter monsoon index and its interannual variability. Chinese $\mathrm{J}$ Atmos Sci 36:523-538 (in Chinese)

Hori ME, Ueda H (2006) Impact of global warming on the East Asian winter monsoon as revealed by nine coupled atmosphereocean GCMs. Geophys Res Lett 33:L03713. doi:10.1029/200 5GL024961

Hu ZZ, Yang S, Wu RG (2003) Long-term climate variations in China and global warming signals. J Geophys Res 108:4614. doi:10.10 29/2003JD003651

Inoue T, Matsumoto J (2004) A comparison of summer sea level pressure over East Eurasia between NECP/NCAR reanalysis and ERA-40 for the period 1960-99. J Meteorol Soc Jpn 82:951-958

Jhun JG, Lee EJ (2004) A new East Asian winter monsoon index and associated characteristics of the winter monsoon. J Clim 11:711-726

Kalnay ET, Kanamitsu M, Kistler R et al (1996) The NCEP/NCAR 40-year reanalysis project. Bull Am Meteorol Soc 77:437-471

Kerr RA (2000) A North Atlantic climate pacemaker for the centuries. Science 288:1984-1985. doi:10.1126/science.288.5473.1984

Kushnir YC, Lau NC (1992) The general circulation model response to a north Pacific SST anomaly: dependence on time scale and pattern polarity. J Clim 5:271-283

Latif M (2006) On North Pacific multidecadal climate variability. J Climate 19:2906-2915

Latif M, Barnett TP (1994) Causes of decadal climate variability over the North Pacific and North America. Science 266:634-637

Latif M, Barnett TP (1996) Decadal climate variability over the North Pacific and North America: dynamics and predictability. J Climate 9:2407-2423

Lau KM, Li MT (1984) The monsoon of East Asia and its global associations. Bull Am Meteorol Soc 65:114-125

Lau NC, Nath WJ (1994) A modeling study of the relative roles of tropical and extratropical in the variability of the global atmosphere-ocean system. J Clim 7:1184-1207

Lau KM, Weng HY (2002) Recurrent teleconnection patterns linking summertime precipitation variability over East Asia and North America. J Meteorol Soc Jpn 80(6):1309-1324
Li CY (1990) Interaction between anomalous winter monsoon in East Asia and El Niño events. Adv Atmos Sci 7:36-46

Li CY, Mu MQ (2000) Relationship between East Asian winter monsoon, warm pool situation and ENSO cycle. Chin Sci Bull 45(16):1448-1455

Li SL, Lu J, Huang G et al (2008) Tropical Indian Ocean basin warming and East Asian summer monsoon: a multiple AGCM study. J Clim 21:6080-6088. doi:10.1175/2008JCLI2433.1

Li HM, Dai AG, Zhou TJ et al (2010) Responses of East Asian summer monsoon to historical SST and atmospheric forcing during 1950-2000. Clim Dyn 34:501-514. doi:10.1007/ s00382-008-0482-7

Li F, Wang HJ, Liu JP (2014) The strengthening relationship between arctic oscillation and ENSO after the mid-1990s. Int J Climatol $34: 2515-2521$

Liu JP, Curry JA, Wang HJ et al (2012) Impact of declining Arctic sea ice on winter snowfall. Proc Natl Acad Sci 109:4047-4079. doi:10.1073/pnas.1114910109

Lu RY, Dong BW, Ding H (2006) Impact of the Atlantic Multidecadal Oscillation on the Asian summer monsoon. Geophys Res Lett 33:L24701. doi:10.1029/2006GL027655

Ma ZG, Shao LJ (2006) Relationship between dry/wet variation and the Pacific Decade Oscillation (PDO) in northern China during the last 100 years. Chin J Atmos Sci 30:464-474 (in Chinese)

Matsumoto J (1992) The seasonal changes in Asian and Australian monsoon regions. J Meteorol Soc Jpn 70:257-273

Overland JE, Adams JM, Bond NA (1999) Decadal variability of the Aleutian low and its relation to high-latitude circulation. J Clim 12:1542-1548

Pak G, Park YH, Vivier F et al (2014) Regime-dependent nonstationary relationship between the East Asian winter monsoon and North Pacific Oscillation. J Clim 27:8185-8204

Palmer TN, Sun ZB (1985) A modeling and observational study of the relationship between sea surface temperature in the northwest Atlantic and atmospheric general circulation. Q J R Meteorol Soc 111:947-975

Peng SL, Mysak LA, Ritchie H et al (1995) The differences between early and midwinter atmospheric responses to sea surface temperature anomalies in the northwest Atlantic. J Clim 8:137-157

Peng SL, Robinson WA, Hoerling MP (1997) The modeled atmospheric response to midlatitude SST anomalies and its dependence on background circulation states. J Clim 10:971-987

Shi N (1996) Features of the East Asian winter monsoon intensity on multiple time scale in recent 40 years and their relation to climate. J Appl Meteorol Sci 7:175-182 (in Chinese)

Smith TM, Reynolds RW (2003) Extended reconstruction of global sea surface temperatures based on COADS data (1854-1997). J Clim 16:1495-1510

Sun JQ (2014) Record-breaking SST over mid-North Atlantic and extreme high temperature over the Jianghuai-Jiangnan region of China in 2013. Chin Sci Bull 59:3465-3470. doi:10.1007/ s11434-014-0425-0

Sun JQ, Ao J (2013) Changes in precipitation and extreme precipitation in a warming environment in China. Chin Sci Bull 58:674-679

Sun BM, Li CY (1997) Relationship between the disturbances of East Asian trough and tropical convective activities in boreal winter. Chin Sci Bull 42:500-504

Sun JQ, Wang HJ, Yuan W (2009) Role of the tropical Atlantic sea surface temperature in the decadal change of the summer North Atlantic Oscillation. J Geophys Res 114:D20110. doi:10.1029/2 009JD012395

Sutton RT, Hodson DLR (2005) Atlantic Ocean forcing of North American and European summer climate. Science 309:115-118

Tao SY, Chen LX (1987) A review of recent research on the East Asian summer monsoon in China. In: Chang CP, Krishnamurti 
TN (eds) Monsoon meteorology. Oxford University Press, Oxford, pp 60-92

Ting MF (1991) The stationary wave response to a midlatitude SST anomaly in an idealized GCM. J Atmos Sci 48:1249-1275

Trenberth KE, Hurrell J (1994) Decadal atmosphere-ocean variations in the Pacific. Clim Dyn 9:303-319

Uppala SM, Kallberg PW, Simmons AJ et al (2005) The ERA-40 re-analysis. Q J R Meteorol Soc 131:2961-3012. doi:10.1256/ qj.04.176

Walker GT, Bliss EW (1932) World weather V. Mem R Meteorol Soc 4:53-84

Wang HJ (2001) The weakening of Asian monsoon circulation after the end of 1970's. Adv Atmos Sci 18:376-386. doi:10.1007/ BF02919316

Wang HJ, He SP (2012) Weakening relationship between East Asian winter monsoon and ENSO after mid-1970s. Chin Sci Bull 57:3535-3540

Wang YM, Li SL, Luo DH (2009a) Seasonal response of Asian monsoonal climate to the Atlantic Multidecadal Oscillation. J Geophys Res 114:D02112. doi:10.1029/2008JD010929

Wang L, Chen W, Zhou W et al (2009b) Interannual variations of East Asian trough axis at $500 \mathrm{hPa}$ and its association with the East Asian winter monsoon pathway. J Clim 22:600-614

Wang T, Wang HJ, Otterå OH et al (2013) Anthropogenic agent implicated as a prime driver of shift in precipitation in eastern China in the late 1970s. Atmos Chem Phys 13:12433-12450

Watanabe M, Nitta T (1999) Decadal change in the atmospheric circulation and associated surface climate variations in the Northern Hemispheric winter. J Clim 12:494-510

Wu BY, Huang RH (1999) Effects of the extremes in the North Atlantic Oscillation on East Asia winter monsoon. Chin J Atmos Sci 23(6):641-651 (in Chinese)

Wu RG, Wang B (2002) A contrast of the East Asian summer monsoon-ENSO relationship between 1962-1977 and 1978-1993. J Clim 15:3266-3279

Xu JJ, Zhu QG, Zhou TH (1999) Sudden and periodic changes of East Asian winter monsoon in the past century. Q J Appl Meteorol Sci 10(1):1-8 (in Chinese)
Yang FL, Lau KM (2004) Trend and variability of China precipitation in spring and summer: linkage to sea surface temperatures. Int $\mathbf{J}$ Climatol 24:1625-1644

Yang S, Lau K, Kim K (2002) Variations of the East Asian jet stream and Asian-Pacific-American winter climate anomalies. J Clim 15:306-325

Yang XQ, Xie Q, Zhu YM et al (2005) Decadal-to-interdecadal variability of precipitation in North China and associated atmospheric and oceanic anomaly patterns. Chin J Geophys 48:789-797

Zhang RH, Levitus S (1997) Structure and cycle of decadal variability of upper-ocean temperature in the North Pacific. J Clim 10:710-727

Zhang RH, Sumi A, Kimoto M (1996) Impact of El Niño on the East Asian monsoon: a diagnostic study of the ' $86 / 87$ and ' $91 / 92$ events. J Meteorol Soc Jpn 74:49-62

Zhang Y, Wallace JM, Battisti DS (1997a) ENSO-like interdecadal variability: 1900-1993. J Clim 10:1004-1020

Zhang Y, Sperber KR, Boyle JS (1997b) Climatology and interannual variation of the East Asian winter monsoon: results from the 1979-1995 NCEP/NCAR reanalysis. Mon Weather Rev 125:2605-2619

Zhao P, Yang S, Wu RG et al (2012) Asian origin of interannual variations of summer climate over the extratropical North Atlantic Ocean. J Clim 25:6595-6609

Zhou W, Li CY, Wang X (2007) Possible connection between Pacific Oceanic interdecadal pathway and east Asian winter monsoon. Geophys Res Lett 34:L01701. doi:10.1029/2006GL027809

Zhou TJ, Yu RC, Zhang J et al (2009) Why the western Pacific subtropical high has extended westward since the Late 1970s. J Clim 22:2199-2215

Zhu YL, Wang HJ, Zhou W, Ma JH (2011) Recent changes in the summer precipitation pattern in East China and the background circulation. Clim Dyn 36:1463-1473 